\title{
EVALUATION OF THE BATTERIES AND CHARGE CONTROLLERS IN SMALL STAND-ALONE PHOTOVOLTAIC SYSTEMS
}

\author{
Joseph R. Woodworth, Michael G. Thomas, John W. Stevens: Sandia National Laboratories \\ Steven R. Harrington: K-Tech Corporation at Sandia National Laboratories \\ James P. Dunlop, M. Ramu Swamy, Leighton Demetrius: Florida Solar Energy Center
}

\begin{abstract}
In this paper, we report the results of long-term tests on 14 separate small stand-alone PV systems. These tests were carried out at two separate laboratories in Albuquerque, New Mexico and in Cape Canaveral, Florida. The systems were heavily instrumented to help determine what effects voltage regulation set points have on system water loss, battery capacity lifetime and system reliability. We find that under the proper conditions, the flooded lead-acid batteries in these PV systems can achieve cycle-lifetimes comparable to manufacturer's expectations for conventional battery applications. We also find that both the overcharge and overdischarge protection provided by the system charge controllers were necessary for proper operation of these systems. Details of the data and a number of conclusions for system designers are presented.
\end{abstract}

\section{INTRODUCTION}

Early loss of battery capacity is one of the most common problems restricting the use of small stand-alone PV systems, both in developed countries and in third world applications. 1,2,3.4 A better understanding of how charge controller settings and algorithms affect specific types of batteries would allow users to improve PV system reliability and achieve more predictable battery lifetimes.

In this paper we report the results of two separate long-term tests of flooded lead-acid batteries and charge controllers in fourteen separate PV systems. Previous papers $5,6,7$ have reported shorter term experiments involving batteries and charge controllers and given an interim report on the tests reported in this paper. The tests reported here, which were designed to evaluate what parameters affect a battery's stateof-charge, lifetime, and water loss, were performed at Sandia National Laboratories (Sandia) in Albuquerque, New Mexico and at the Florida Solar Energy Center (FSEC) in Cape Canaveral, Florida. Seven complete stand-alone PV systems were tested at each location. The tests lasted slightly less than two years at each location, with the systems operating at Sandia from November 1990 to October 1992 and at FSEC from November 1991 to August 1993.

\section{SYSTEM DESCRIPTION}

Each stand-alone PV system consisted of a photovoltaic array, a battery, a charge controller and a resistive load. A simplified schematic of a typical system is shown in Figure 1.

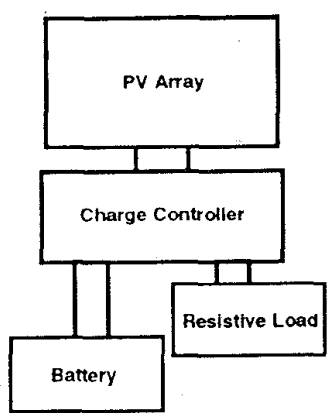

Figure 1: Schematic of typical PV system

Batteries

The batteries in all of these tests were the Trojan Battery Company's "Pacer" $30 \mathrm{XH}$ batteries. ${ }^{8}$ These 12 -volt batteries have a rated capacity of 105 amp-hrs at a 20 -hr discharge rate and $110 \mathrm{amp}$-hrs at a 100-hr discharge rate. They have lead-antimony plates $(6 \%$ antimony in positive plates, $2.75 \%$ antimony in negative plates). The $30 \mathrm{XH}$ batteries were chosen for these experiments because they resembled deepcycle batteries in many respects, but have relatively thin plates and hence would be expected to approach end-of-life during the course of the two-year-long experiments. When subjected to a daily depth of discharge of $15 \%$, as was the case in the Sandia experiments, Trojan suggests that these batteries will have a cycle life of approximately 900 cycles - i.e. after 900 cycles, the battery's capacity will have been reduced to $-50 \%$ of its original value, with complete failure of the battery expected to occur relatively rapidly thereafter.

In these tests, we refer both to battery "capacity" and battery "state-of-charge." In this paper, these terms are defined as follows:

1. Battery capacity. The number of amp-hours that can be withdrawn from a battery at a specified discharge rate, before the battery drops to a specified low voltage after the battery has been charged by a power supply that provides both bulk and finishing charge cycles. At Sandia, battery capacity measurements involved two steps. First, the battery was charged by a power supply at 7 amps to 14.4 volts and then held at 14.4 volts for 30 hours. Second, the battery was discharged at a 5-amp rate until the battery voltage dropped to 10.75 
volts. The amp-hrs withdrawn from the battery in the second half of the test were defined as the battery capacity.

2. Battery state-of-charge: The number of amphours that can be withdrawn from a battery at the time of a particular test, when the battery is discharged at a specified rate to a. specified low voltage. At Sandia, the batteries were discharged at a 5 -amp rate to 10.75 volts. Note that there is no restriction in the state-of-charge measurements on how the battery was treated prior to being discharged. Battery capacity can be measured only after carefully charging the battery. Battery stateof-charge can be measured anytime. In this paper, battery state-of-charge is expressed as a fraction of the batteries' initial capacity.

\section{Loads}

Both experiments used fixed resistors as the loads for these PV systems. At Sandia, the loads drew 1.0 Amps of current from the system 24 hours a day for a total daily load of 24 amp-hrs. At FSEC, the loads were connected to the system only at night, drawing 2.75 amperes for 8 hours producing a total daily load of 22.3 amp-hrs. The FSEC loads approximated the loads found in PV lighting systems. The Sandia loads approximated the loads found in communications systems. This difference in load timing caused important differences in the system operation, which will be discussed in the results section.

\section{PV Arrays}

At FSEC, each system was powered by two Solarex MSX 60 modules in parallel, with a combined maximum-power output of $15.9 \mathrm{~V}, 6.26 \mathrm{~A}$ and 100 watts at standard test conditions $\left(25^{\circ} \mathrm{C}, 1000 \mathrm{~W} / \mathrm{m}^{2}\right.$ solar irradiance). At Sandia, each system was powered by four Solarex 5-volt, 60-watt modules wired in series with cell shading over parallel strings to reduce the current output. These systems had relatively long wiring runs between the arrays and controllers, further reducing the array output. As a result, the arrays at Sandia provided a maximum power output measured at the charge controller connections of 15 volts, 6.3 amps and 90 watts at standard test conditions.

\section{Charge Controllers}

Charge controllers with a variety of operating algorithms were purchased from seven different manufacturers:

\author{
Bobier Electronics ${ }^{9}$ \\ BOSS $^{10}$ \\ Heliotrope General ${ }^{11}$ \\ Integrated Power Corporation ${ }^{12}$ \\ Polar Power ${ }^{13}$ \\ Specialty Concepts Inc. ${ }^{14}$ \\ SunAmp ${ }^{15}$
}

Since the charge controllers at Sandia and FSEC were purchased a year apart, they were not identical at the two locations. However, the controllers in systems 1 through 5 at Sandia and FSEC were from the same manufacturers (i.e. the controller in system \#1 was from the same manufacturer at Sandia and FSEC, the controller in system \#2 was from the same manufacturer at Sandia and FSEC . . etc.). In addition, systems 2 through 5 had settings close enough that they can be used to directly compare data from the two sites.

The controllers used in these experiments had four set points:

- "Vr" regulation voltage - voltage at which the controller disconnects the array from the battery to protect the battery from overcharging.

- "Vrr" regulation reconnect voltage - voltage at which the controller reconnects the array to the battery to begin full current charging again.

- "LVD" low voltage disconnect - voltage at which the controller disconnects the battery from the load to prevent over-discharging of the battery.

- "LVR" low voltage reconnect - voltage at which the controller reconnects the battery to the load.

Controllers 3 and 7 at Sandia did not initially have low-voltage disconnects. After these batteries were drained to $\sim 1.5 \mathrm{~V}$ in January of 1991 during a period of cloudy weather, external low-voltage disconnects were added.

Two basic types of charge controller algorithms were used in this experiment.

1. "Off-on" controllers applied either the full array current or no current to the battery depending upon the battery voltage. The difference between $\mathrm{Vr}$ and $\mathrm{Vrr}$ in these controllers varied from $0.1 \mathrm{~V}$ to $1.7 \mathrm{~V}$. The controllers with large $\mathrm{Vr}-\mathrm{Vrr}$ differences $(0.8 \mathrm{~V}$ or greater) cycled off and on during regulation with a frequency of 0.1 cycles/sec or less. The two controllers with small $\mathrm{Vr}$ - Vrr differences $(0.1$ to $0.3 \mathrm{~V})$ were called by the manufacturers "constant voltage" (CV) and "pulse width modulated" (PWM). However, observation of these controllers' operating characteristics on an oscilloscope indicate that they are off-on controllers operating at high frequency ( $400 \mathrm{cycles} / \mathrm{sec}$ ) with the exact frequency being a function of the battery state-of-charge, charge rate and the controller setpoints.

2. A current limiting controller ( \#7) at FSEC applied full array current up to the battery's regulation voltage and then limited the charging current to 1 ampere.

Tables I and II list the charge controller set points for the tests at Sandia and FSEC respectively. Calibration of the charge controller set points was accomplished prior to the experiment by the techniques described in Bower, Dunlop and Maytrott. "However, the Vr. Vrr and LVD values at FSEC 
Table 1: Settings for SNL Phase 1 Charge Controllers

\begin{tabular}{ccccccc}
$\begin{array}{c}\text { System } \\
\#\end{array}$ & Algorithm & Temperature & \multicolumn{5}{c}{ Values at charge controller } \\
& & Compensation & \multicolumn{3}{c}{ terminals (volts at 25 C) } \\
1 & off-on & no & 14.25 & 12.9 & 12.3 & 10.8 \\
2 & off-on & internal to CC & 14.54 & 13.45 & 12.44 & 11.83 \\
3 & off-on PWM & no & 14.4 & 14.1 & 12.3 & 10.8 \\
4 & off-on CV & yes-at battery & 14.4 & 14.3 & 13.4 & 11.8 \\
5 & off-on & no & 14.36 & 13.45 & 13.15 & 11.48 \\
6 & off-on & yes-at battery & 14.4 & 12.66 & 13.63 & 11.60 \\
7 & off-on & yes-but & 14.35 & 13.15 & 12.3 & 10.8 \\
& & $\begin{array}{l}\text { temperature } \\
\text { probe in CC rm. }\end{array}$ & & & &
\end{tabular}

Table II: Settings for FSEC Phase 2 Charge Controllers

\begin{tabular}{|c|c|c|c|c|c|c|c|}
\hline \multirow[t]{2}{*}{$\begin{array}{c}\text { System } \\
\#\end{array}$} & \multirow[t]{2}{*}{ Algorithm } & \multirow[t]{2}{*}{$\begin{array}{l}\text { Temperature } \\
\text { compensation }\end{array}$} & \multicolumn{4}{|c|}{$\begin{array}{l}\text { Values at charge controller } \\
\text { terminals (volts at } 25 \mathrm{C} \text { ) }\end{array}$} & \multirow{2}{*}{$\begin{array}{c}\text { Values at } \\
\text { battery }(25 \mathrm{C}) \\
\mathrm{Vr}\end{array}$} \\
\hline & & & $\mathrm{Vr}$ & Vrr & LVR & LVD & \\
\hline 1 & $\begin{array}{l}\text { off-on } \\
\text { 2-step }\end{array}$ & $\begin{array}{l}\text { at battery for } 1 \text { st } 9 \\
\text { months, none } \\
\text { after } 9 \text { months }\end{array}$ & $\begin{array}{l}>15.0^{\star} \\
14.28 / 13.8^{\star}\end{array}$ & $\begin{array}{l}\sim 13.8 \\
13.4\end{array}$ & 12.4 & 11.0 & $\begin{array}{l}14.7^{\star} \\
14.0 / 13.54^{\star}\end{array}$ \\
\hline 2 & off-on & internal to $\mathrm{CC}$ & 14.57 & 13.46 & 12.1 & 11.6 & 14.21 \\
\hline 3 & off-on PWM & yes- at battery & 14.5 & 14.1 & 12.8 & 11.2 & 14.4 \\
\hline 4 & off-on CV & internal to $\mathrm{CC}$ & 14.4 & 14.4 & 12.8 & 11.5 & 14.35 \\
\hline 5 & off/on & yes - at battery & 14.7 & 13.8 & 12.7 & 11.45 & 14.45 \\
\hline 6 & off/on & none & $\begin{array}{l}-14.5^{\star \star} \\
14.88^{\star \star}\end{array}$ & $\begin{array}{l}\sim 13.0^{\star \star} \\
13.72^{\star \star}\end{array}$ & $\begin{array}{l}12.3- \\
12.5\end{array}$ & 11.7 & $\begin{array}{l}-14.2^{\star \star} \\
14.58^{\star \star}\end{array}$ \\
\hline 7 & $\begin{array}{l}\text { current } \\
\text { limiting }\end{array}$ & $\begin{array}{l}\text { external at } \\
\text { battery }\end{array}$ & $\begin{array}{l}14.4^{\star \star} \\
14.8^{\star \star}\end{array}$ & & 12.7 & 11.1 & $\begin{array}{l}\sim 14.1^{\star \star} \\
14.45^{\star \star}\end{array}$ \\
\hline
\end{tabular}

* Controller was changed during 7/92. 1st line in table gives initial set point, second line gives final set point. After $7 / 92$, controller initially charged battery to upper $\mathrm{Vr}$ set point each day, then regulated between lower $\mathrm{Vr}$ set point and $\mathrm{Vrr}$.

${ }^{\star *}$ Controller settings were changed in $5 / 92$. Ist line gives initial settings, 2nd line gives final settings.

were also determined from actual system operating voltages. In some cases there was a difference of $\sim 0.2 \mathrm{~V}$ in the set point value as determined by the two techniques. In these cases, we used the value obtained from the system operating voltages.
When the array was providing its full output current, resistance in the wiring and fuses and the somewhat smaller resistance of the shunt used to measure battery current, caused $a \sim 0.2 \mathrm{~V}$ voltage drop between the charge controller "battery" terminals and the actual terminals on the battery at Sandia and a $0.3 \mathrm{~V}$ to $0.4 \mathrm{~V}$ drop at FSEC. This effectively lowered the $\mathrm{Vr}$ and raised the LVD of the system. 
Controller \# 1 at FSEC was a two-step off-on controller. It had a higher $V r$ setpoint for the first regulation cycle of each day than for all successive regulation cycles. Initially, however, this controller malfunctioned, rarely went into regulation at all and continued to bulk charge the battery regardless of the battery voltage. This controller was replaced 9 months into the test (July 1992) with a similar controller from the same manufacturer. The two-step regulation did function on this second controller.

Set point changes were also made to systems 6 and 7 at FSEC in May 1992. The top values for Vr and Vrr in Table II are the original settings and the lower values are the final settings.

\section{TEST PROCEDURES}

\section{Battery Initialization}

To be sure that the batteries at each location had equal capacities at the beginning of the tests, the batteries were charged and discharged several times, recording the ampere hours in each charge or discharge cycle. For all of the discharge tests (both in battery initialization and state-ofcharge measurements), the batteries were discharged in twohour increments, with the batteries being allowed to rest for one hour between discharge periods. Thus, during discharge, the batteries were repeatedly discharged for two hours, allowed to rest for one hour and then discharged for two more hours until the battery voltage reached the lower cutoff voltage during the first 15 minutes of a two-hour cycle. The off-on cycling in the discharge tests was designed to measure battery internal resistance as a function of stateof-charge by measuring battery voltage under load and in open-circuit conditions at a number of different states of charge. For tests designed only to measure state-of-charge, a much simpler discharge at a constant current to a fixed low-voltage cutoff would have been adequate. When all of the battery capacities were within $2 \%$ of each other at each location, the batteries were declared ready for the long-term tests.

At Sandia, batteries were put through nine initial charge/ discharge cycles. The Sandia batteries were charged at 7 amps to 14.4 volts and then held at 14.4 volts for 30 hours. The Sandia batteries were discharged at 5 amps to a cutoff voltage of 10.75 volts. At the beginning of the initialization tests, the Sandia battery capacities varied from 76 to $86 \mathrm{amp}$ hrs. At the end of the initialization tests, all the batteries had capacities between 92 and 94 amp-hrs, with an average of 93 amp hrs.

At FSEC, the batteries were put through five initial charge/ discharge cycles. The FSEC batteries were also charged at 7 amps to 14.4 volts and then held at this voltage for 30 hours. The FSEC batteries were discharged at 5 amps to a cutoff voltage of 10.7 volts. At the beginning of the initialization tests, the FSEC battery capacities varied from 94 to 99 amp-hrs. At the end of the initialization tests, all the FSEC batteries had capacities between 97 and $100 \mathrm{amp}-$ hrs, with an average of 98.5 amp-hrs.

\section{State-of-Charge Measurements}

At Sandia, the following procedure was used to determine battery state-of-charge:

1. At the end of five sunny days, the batteries were isolated from the PV systems.

2. The next morning, battery open-circuit voltage was measured and specific gravity measurements were taken using a refractometer.

3. The discharge test load was configured for a 5-amp discharge current, and the discharging began, in its 2hours-on, one-hour-off cycle until the battery reached 10.75 volts in the first 15 minutes of a discharge period.

4. The batteries were then connected in series, recharged until the average battery voltage was 14.4 volts and held at this voltage level for 10 hours.

5. Battery water was added and documented.

6. Batteries were returned to the PV systems.

At FSEC, the following procedure was used to determine battery state-of-charge:

1. The systems were normally allowed to run with the loads disconnected for three to five days prior to testing.

2. The PV arrays were disconnected the evening before the state-of-charge test.

3. The next morning, specific gravities were measured with a refractometer and the loads were configured to provide a 5-amp discharge rate, with the system cycling two hours on and one hour off until it reached $10.7 \mathrm{~V}$ in the first 15 minutes of a two-hour discharge cycle.

4. The batteries were recharged in two groups, with up to 4 batteries in series, at a 7 -amp rate until the average battery voltage in each group was 14.4 volts. The batteries were then held at this voltage level for approximately 20 hours.

5. Battery water was added and documented

6. The batteries were then returned to the systems.

Note that the battery recharges described here probably did not provide complete equalization charging. Trojan Battery Corporation informs us that in order to equalize these batteries, it is necessary to hold them at a charge voltage of $15.4 \mathrm{~V}$ for several hours. ${ }^{16}$

The three-to-five days that the FSEC systems ran without the loads prior to state-of-charge testing probably yielded results that were somewhat higher than the normal system state-of-charge. This will be discussed further in the next section.

\section{RESULTS}

Figure 2 shows a sampling of the raw data from system number two at FSEC for three sunny days in July of 1992. This figure shows six-minute averages of battery voltage (measured at the controller terminals), battery current, current from the PV array, load current, tilt irradiance (solar irradiance at the plane of the PV array), and battery temperature. 

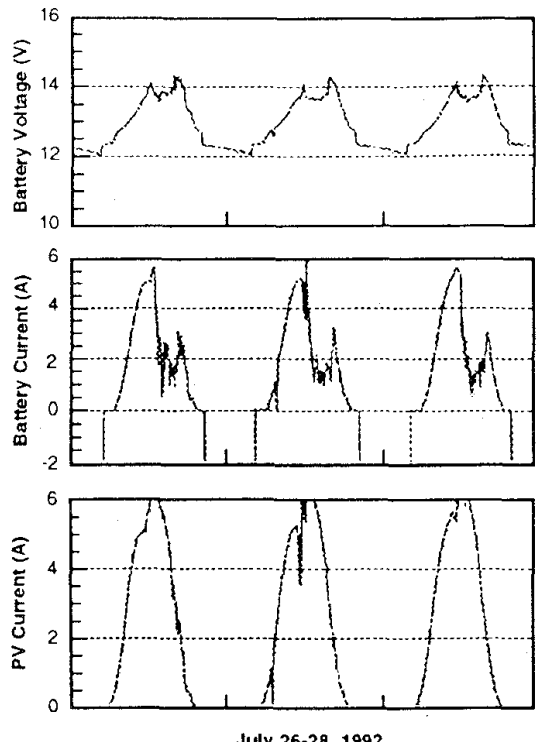
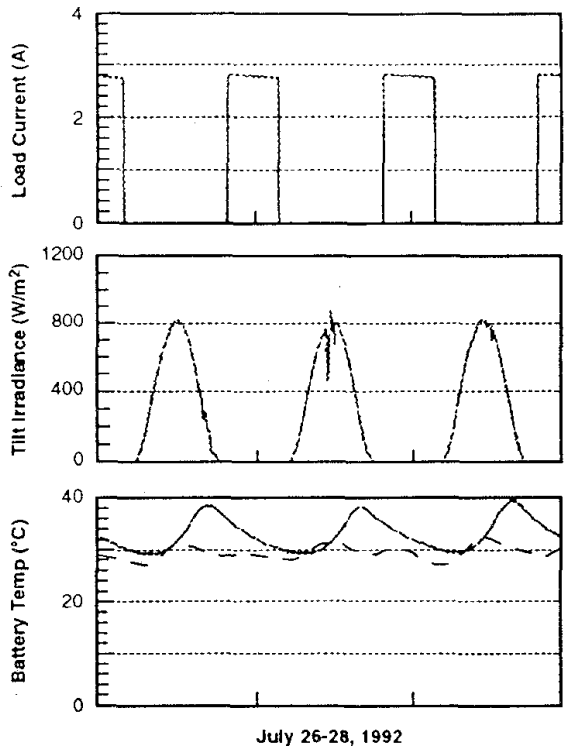

Figure 2: Raw data from system tests at FSEC; 6-minute averages of PV, battery \& load current, battery voltage, solar irradiance at the plane of the array and battery temperature. Battery room temperature is also shown as a dashed curve under the curve of battery temperature.

Battery voltage, battery current and PV current all rise with the tilt irradiance in the mornings as the battery receives bulk charging to replace the energy dissipated by the load the previous evening. About noon, the charge controller goes into its regulation cycle. While the off-on cycling during regulation is too fast to be resolved in this six-minute average data, the data still displays a number of interesting trends. The average battery voltage drops as soon as regulation starts and does not rise again until the system quits regulating near sunset. Since the controller on this system is a "shunt" controller, which short-circuits the array during regulation, the battery current drops and the array current rises to its short-circuit current value during regulation. In the evening, the battery voltage first drops sharply from $\sim 12.8 \mathrm{~V}$ to $\sim 12.4$ $V$ as the load is connected and then drops slowly to $\sim 12.1 \mathrm{~V}$ during the 8 hours that the load is on. When the load is disconnected, the battery voltage recovers to an equilibrium value of $\sim 12.4 \mathrm{~V}$ and remains there until sunrise.

Battery temperature is influenced by two factors: the temperature in the battery room and the fact that charging batteries is an exothermic process. In the three days shown in Figure 2, temperature in this east-facing battery room begins rising at about 7 a.m. or one hour after sunrise, peaks at $\sim 32^{\circ} \mathrm{C}$ about 1 p.m. and then slowly decays to an overnight low of $-28^{\circ} \mathrm{C}$. Thus, the batteries at FSEC are above room temperature for all but one or two hours in the early afternoon. During the night, the battery temperature slowly drops toward room temperature, reaching an overnight low of $\sim 30{ }^{\circ} \mathrm{C}$ about 8 a.m. Battery temperature then begins rising as the battery is charged, peaking at $\sim 39^{\circ} \mathrm{C}$ at sunset. Note that the battery temperature continues to rise sharply while the system is in regulation, despite the fact that the average current entering the battery has been reduced more than a factor of 2 . The data in Figure 2 represent three completely sunny days. On days that are partly or completely cloudy, the battery temperature is much closer to room temperature.

Figure 3 shows plots of battery voltage measured at the battery terminals and battery current for system number 2 at FSEC on July 23,1992 . This data was taken with a $\sim 10-$ second time resolution, fast enough to observe the off-on cycling as this system starts regulation. The full-on, full-off

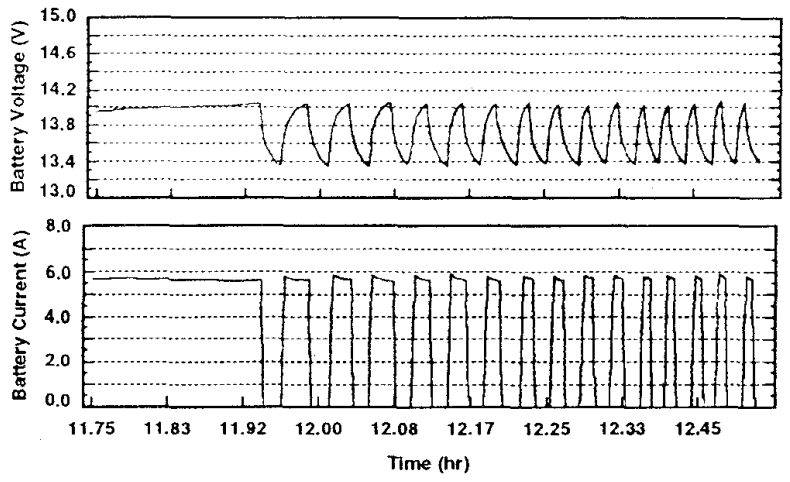

Figure 3: Battery voltage (measured at battery terminals) and battery current on system \#2 at FSEC as the system begins regulating on a sunny day in July 1992 . 
nature of this system during regulation is clearly evident in the battery current. The regulation reconnect voltage (Vrr) of 13.4 is also evident from the voltage trace. The peak battery voltage shown in Figure 3 is gradually rising toward its maximum voltage of $14.26 \mathrm{~V}$, which will be achieved as the regulation cycle occurs with higher frequency later in the day.

Figure 4 shows the measured solar irradiance on the plane of the arrays at Sandia and FSEC. This graph, which shows monthly averages of irradiance, indicates that it is considerably sunnier at Sandia, in Albuquerque, NM than it is at FSEC, in Cape Canaveral, FL. Photovoltaic system designers normally size a system by looking at the ratio of array energy supplied to load energy consumed in the worst month of an average or "typical meteorological" year. PVCAD software ${ }^{17}$ was used to predict the array to load ratios of these systems. The typical meteorological year data in PVCAD indicated that the Sandia systems should have a worst month array to load ratio of 1.40 to 1 and the FSEC systems should have a ratio of 1.19 to 1 . Recent "typical meteorological year" data published by the National Renewable Energy Laboratory ${ }^{18}$ suggest that the Sandia systems should have a worst month array-to-load ratio of 1.31 to 1 and the FSEC systems should have a ratio of 1.15 to 1 .

For the batteries, PV arrays and loads in these experiments, we would initially expect the batteries to see an average daily depth of discharge of 22 to 24 amp-hrs, equivalent to 20 to $22 \%$ of the batteries' rated capacity, at FSEC and Sandia respectively. For the FSEC systems this is correct. For the Sandia systems, however, the situation is more complex, since the loads at Sandia drew current 24 hours a day. Some of the current generated by the Sandia arrays during the day went directly to the load, bypassing the battery and reducing the average daily depth of discharge. PVCAD predicts that this effect will lower the daily depth of discharge

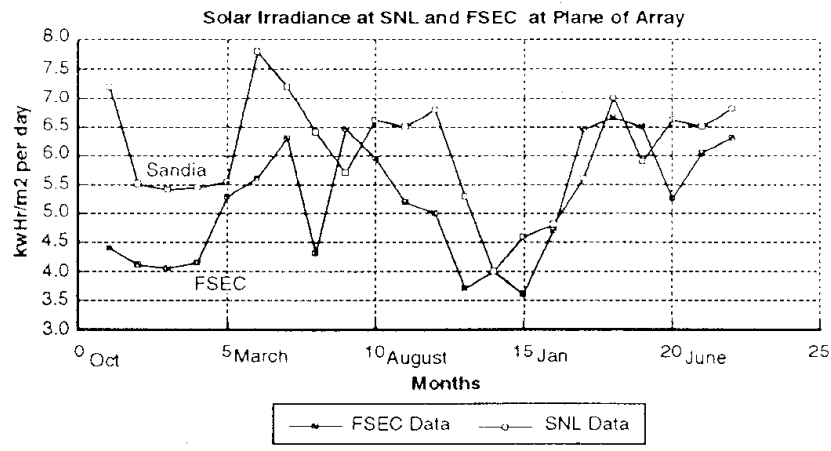

Figure 4: Solar irradiance at the plane of the arrays at Sandia and FSEC. Note that there is consistently more solar energy available at Sandia

at Sandia to $15 \%$ of the batteries' rated capacity. Analysis of the time the Sandia systems spent in bulk charging and in regulation in 1991 supports the PVCAD prediction. Thus, while the FSEC and Sandia systems had nominally identica! PV arrays, batteries and daily load amp-hours, the difference in load timing caused significantly shallower daily depth of discharge cycles in the Sandia batteries than in the FSEC batteries.

Table III shows the total amount of water that was added to each of the systems at Sandia and FSEC over the course of the 23 months of testing. Note that the average water usage at $\mathrm{FSEC}$ is about $60 \%$ greater than the average water use at Sandia.

Figure 5 shows weekly averages of daily maximum and minimum battery temperatures at Sandia and FSEC. Weekly averages of daily maximum outside ambient temperatures are also shown at Sandia for comparison. The Sandia data is for 1991, the FSEC data is for 1992. While the Sandia temperature data is incomplete, the battery and ambient temperature data taken together strongly suggest that for the majority of the summer, battery temperatures at FSEC were significantly higher than at Sandia.

Figure 6 shows outside ambient temperature, battery temperature and charge controller temperature for system \#4 at Sandia during the summer of 1991. This charge controller limited the current during its regulation cycle by pulsing the current on and off at high frequency ( $~ 400$ cycles/ $\mathrm{sec}$ ). The battery temperature, which peaks roughly at sundown, rarely exceeds the ambient temperature by more than $5^{\circ} \mathrm{C}$. The charge controller, however, often rose $\sim 30^{\circ}$ $\mathrm{C}$ above the battery temperature due to heat the controller generated internally. Because of this, controllers that have external temperature probes measuring battery temperature directly appear preferable to controllers which use controller temperature to approximate battery temperature, particularly

Table II!: Total Water addition to batteries during 23 months of testing.

\begin{tabular}{llr} 
System & \multicolumn{2}{l}{ Water Loss (grams) } \\
& Sandia & FSEC \\
1 & 2,268 & 5,726 \\
2 & 2,778 & 4,309 \\
3 & 4,054 & 6,038 \\
4 & 4,365 & 5,669 \\
5 & 2,835 & 4,366 \\
6 & 2,807 & 5,273 \\
7 & 3,090 & 4,139
\end{tabular}




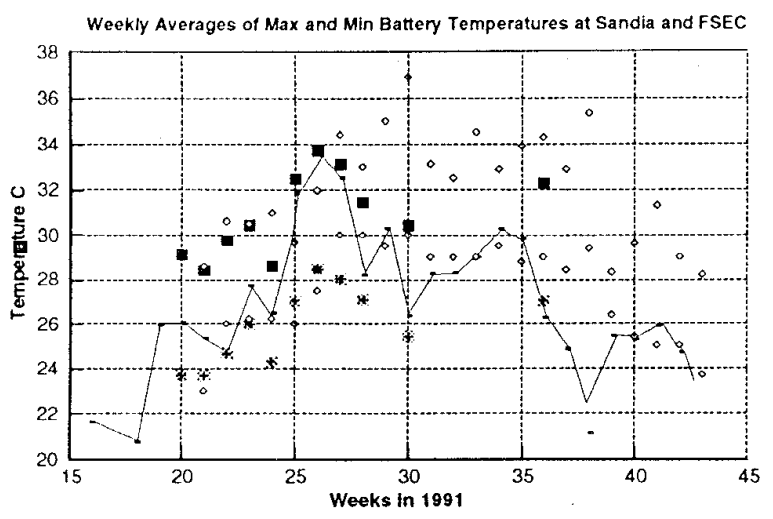

\begin{tabular}{|ll|}
- - Max Outside Temp at Sandia & - Max Temp at Sandia * Min Temo at Sandia \\
$\square$ Max Temp at FSEC & - Min Temp at FSEC \\
\hline
\end{tabular}

Figure 5: Weekly averages of daily maximum and minimum battery temperatures at Sandia and FSEC along with weekly averages of maximum daily outside ambient temperatures at Sandia. Sandia data is for 1991 and FSEC data is for 1992. Note that during July and August, the batteries are significantly hotter at FSEC than at Sandia.

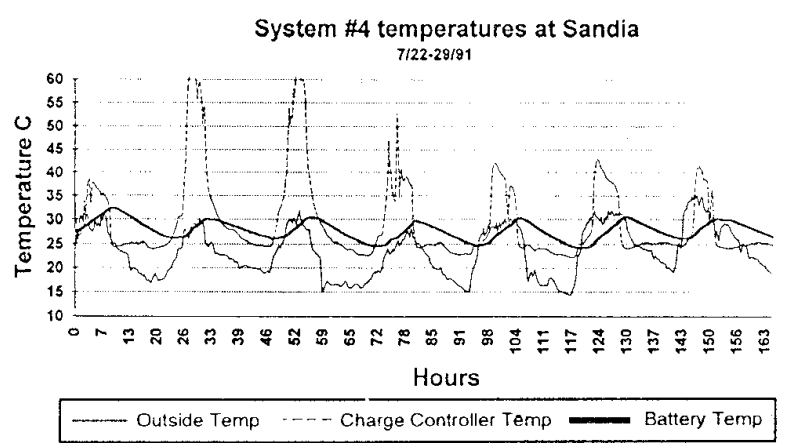

Figure 6: Battery, charge controller and outside ambient temperatures for system \#4 at Sandia. Note that the charge controller temperature often rises $30^{\circ} \mathrm{C}$ above ambient temperatures due to heat generated inside the controller.

for controllers that operate at high frequency or in a linear or resistive current limiting mode.

Figures 7 and 8 are bar charts showing the state-of-charge of the batteries in the Sandia and FSEC systems as a fraction of the initial capacity of each battery. As discussed earlier, these measurements were made by actually discharging the batteries. Since the temperature of the batteries fluctuated significantly from summer to winter during the tests, we have corrected the state-of-charge measurements to $70^{\circ} \mathrm{F}$ using the data given by Perez. ${ }^{19}$ The box under each figure

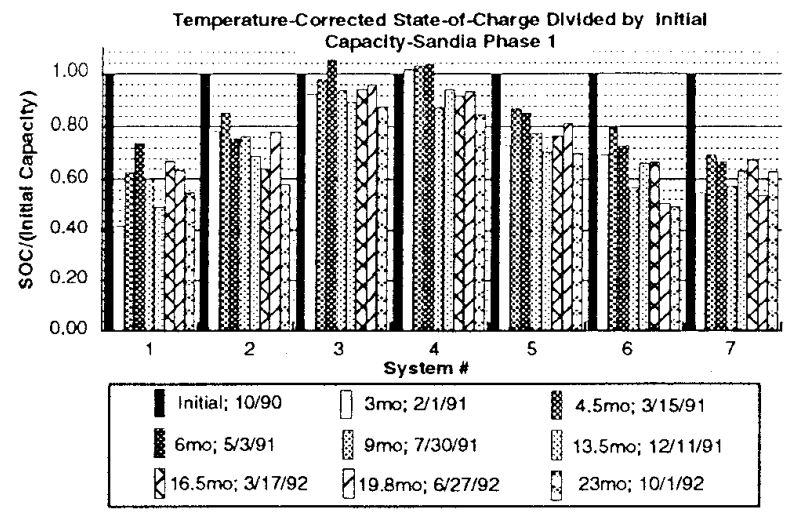

Figure 7: $\quad$ State-of-charge of batteries at Sandia as a fraction of their initial capacity. All state-ofcharge measurements are corrected to $21^{\circ} \mathrm{C}$. Note that some of the Sandia batteries remain at or above $85 \%$ state-of-charge throughout the tests.

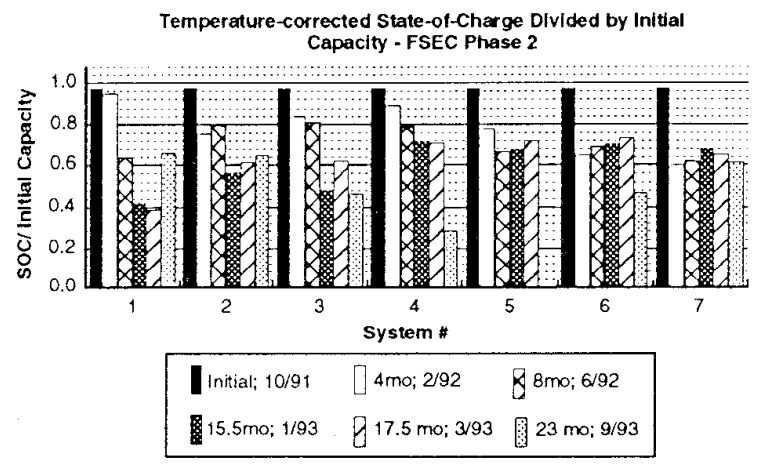

Figure 8: State-of-charge of batteries at FSEC as a fraction of initial capacity corrected to $21^{\circ} \mathrm{C}$ as in Figure 7. Note that the state-of-charge of the batteries has decayed to $\sim 70 \%$ or less by the end of the second winter.

indicates when the state-of-charge measurements were made. Recall that systems 2 through 5 had controllers from the same manufacturers at both locations.

As mentioned previously, the systems at FSEC were normally allowed to run for three to five days with the load disconnected before the state-of-charge tests. This undoubtedly raised the system above its normal state-ofcharge. We can estimate the size of this effect by comparing three battery state-of-charge measurements at FSEC. The first measurement was taken four months into the test after the systems had spent three days without the load. In the second measurement, which was taken eight months into the test, the array and load were disconnected at the same time the evening before the test; The third measurement was also taken at eight months, after a power supply recharge 
in which the batteries were bulk charged to $14.4 \mathrm{~V}$ and then held at $14.4 \mathrm{~V}$ for 30 hours (this third set of data is not shown in Fig. 7). Surprisingly, the solar irradiances at four months (February) and eight months (June) were about the same at FSEC, allowing a meaningful comparison between the two different periods. We conclude that systems 2 through 5 have increased their average state-of-charge by only about $6 \%$ during the three days without a load on the system.

\section{ANALYSIS}

\section{Are charge controllers really necessary?}

The systems described in this paper have battery capacities equal to $\sim 4$ days of load requirements and are typical of many PV systems used for residential or outdoor lighting applications. The function of the charge controllers in these systems is to protect the batteries from overcharge or overdischarge. There are PV designs which operate satisfactorily without charge controllers. As an example, when load requirements are much smaller than in the systems described here, it is often economical to omit the charge controller entirely and use a battery with a capacity of -30 days of load requirements instead. The U. S. Coast Guard has used this type of design in many navigational beacons. While the batteries in these navigational systems do suffer from the effects of overcharging and overdischarging, the relatively large battery capacity allows these systems to continue to operate reliably. ${ }^{20}$

Two systems in this test with malfunctioning or incomplete charge controllers demonstrate why controllers are needed for the types of PV systems tested here. System \#1 at FSEC initially had a malfunctioning controller that rarely regulated at all and which, on most clear days, continued to try to bulk charge the battery until sunset. This led to maximum battery voltages of 15.0 to $15.3 \mathrm{~V}$ on many sunny days, which is excessive for this type of battery. As a result, the battery in system \# 1 had very high water loss ( see Figure 16) and in the post-mortem inspection, the positive grids of this battery were found to be severely corroded. On the other hand. system \# 3 at Sandia initially had no low-voltage disconnect. As a result, the battery in this system was drained to $\sim 1.5 \mathrm{~V}$ during a cloudy period in January 1991 . At $1.5 \mathrm{~V}$, the controller could not operate properly and disconnected the array from the battery, locking the system into a nonfunctioning state. Manual intervention was required to restart the system. An external low-voltage disconnect was added to the system after this incident. Note that this problem, which occurred due to the absence of a low voltage disconnect, occurred on the system which otherwise maintained the highest state-of-charge of any of the fourteen systems in this test.

\section{Set Points}

The differing set points of the systems at Sandia allow us to look at the effect of the set points on the system's state-ofcharge. Figure 9 plots the average system state-of-charge over the 23 months of the test as a function of $V r$. Vrvalues

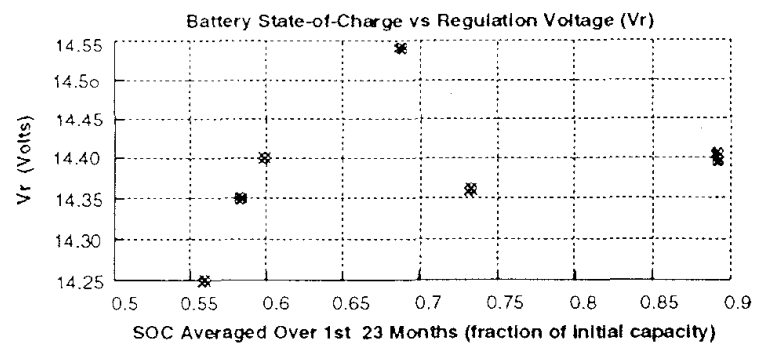

Figure 9: Average state-of-charge of the batteries at Sandia over the 23-month test as a function of regulation voltage ( $\mathrm{Vr}$ ) of the charge controller. Note the absence of any obvious correlation.

at Sandia had been set as close as possible to $14.4 \mathrm{~V}$, therefore we could only examine the effect of Vrover a limited range. Over this limited range, there does not appear to be any correlation between $\mathrm{Vr}$ and state-of-charge. Figure 10 shows a plot of the average system state-of-charge as a function of the value of $\mathrm{Vrr}$, the regulation reconnect voltage. This data shows a strong correlation, with a correlation coefficient $(R)^{21}$ of 0.95 . Analysis of the correlation coefficient and the number of data points indicates that the probability $(P)^{2 l}$ that this apparent correlation is accidental is less than $0.1 \%$. Figure 11 shows a plot of total water loss at Sandia over the 23 months of the experiment as a function of Vrr. Again, we see a significant correlation with $R=0.88$ and $P=$ $1 \%$. Plots of water loss versus $\mathrm{Vr}$ show no obvious correlation for the Sandia data. Finally, Figure 12 shows that system state-of-charge and water loss are also correlated with each other $(R=0.89, P=$ less than $1 \%)$.

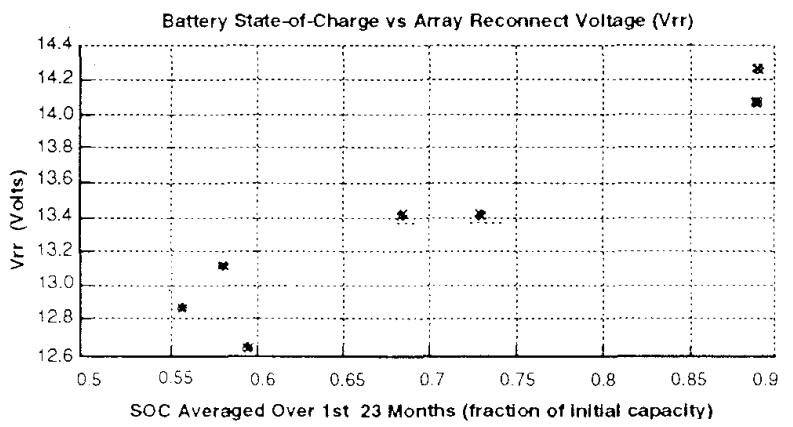

Figure 10: Average state-of-charge of the batteries at Sandia over the 23-month test as a function of regulation reconnect voltage (Vrr). Note that state-of-charge is strongly correlated to Vrr.

Both state-of-charge and water loss are strongly dependent on regulation reconnect voltage, but only weakly dependent on regulation voltage over the range of the $\mathrm{Vr}$ and $\mathrm{Vrr}$ data shown. It appears that the number of times a system cycles off and on during a day in regulation has a much stronger impact on battery state-of-charge than the maximum voltage 


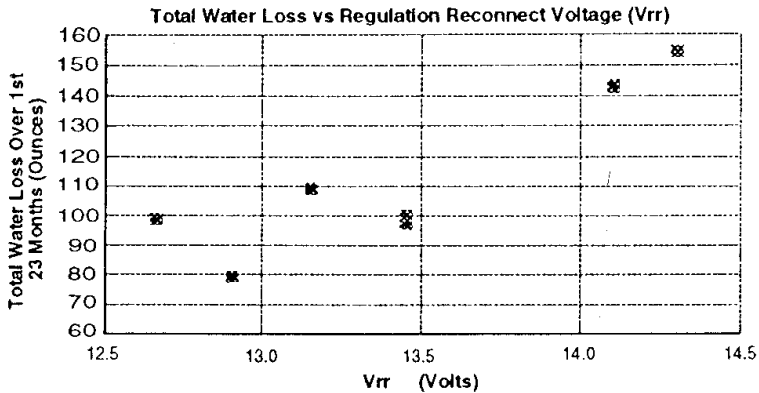

Figure 11: Total water loss in the Sandia PV systems as a function of regulation reconnect voltage. These two variables are also correlated.

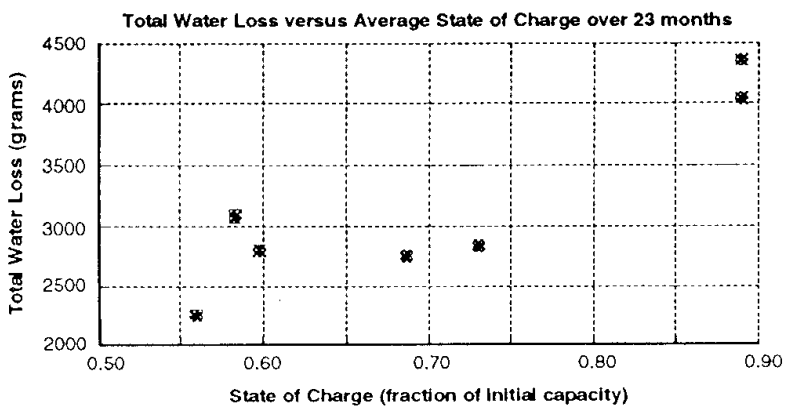

Figure 12: Total water loss in the Sandia PV systems as a function of average state of charge over the 23 months of testing.

reached in any one cycle. Beyond certain limits, it is clear that the value of $\mathrm{Vr}$ will become important. As an example of this, the controller in system \#1 at FSEC, which was malfunctioning during the first nine months of the test, regularly charged its battery to 15.0 to $15.3 \mathrm{~V}$, causing the high water loss and excessive grid corrosion described in the previous section.

During the second winter at FSEC, which had unusually low solar irradiance, most of the systems had their batteries drained to the low-voltage disconnect point 20 or more times. As a result, the value of the low voltage disconnect (LVD) had an impact on the overall health of the battery during this winter and the summer that followed. Figure 13 shows a plot of state-of-charge for five of the off-on controllers averaged over the winter of 1992 and the summer that followed. The sixth off-on controller at FSEC is not included because its system suffered a load failure during this period. Figure 13 demonstrates a clear relationship between the LVD and the long-term battery state-of-charge for these systems ( $R=0.98, P$ is less than $1 \%$ ). Thus, relatively high LVD values appear to protect the long-term health of the battery, but at the expense of decreased load availability.

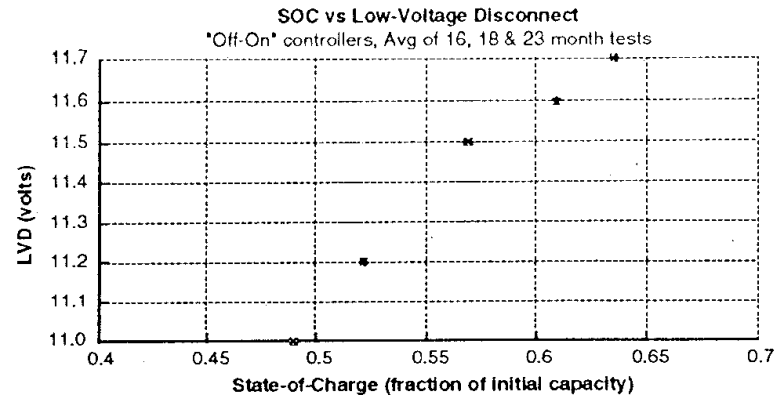

Figure 13: Average state-of-charge for five of the off-on controllers at FSEC as a function of the controller's low voltage disconnect setting (LVD). For systems that spend a significant amount of time in a deficit situation, increasing the value of the low-voltage disconnect improves the long-term health of the battery.

\section{Solar Irradiance Levels}

The differing climate at the two test locations caused very different behavior in the PV systems. As stated earlier, the NREL solar irradiance data suggests that the PV systems should have had worst-month array-to-load ratios of 1.31 to 1 at Sandia and 1.15 to 1 at FSEC. Weather patterns are notoriously variable from year to year however and the NREL irradiance data shows worst-month irradiance at Albuquerque varying by $\sim \pm 25 \%$ about the mean over the years from 1960 to 1991. Measured array-to-load ratios averaged over the 3 worst months of the second winter at each site were 1.21 to 1 at Sandia and only 1.06 to 1 at FSEC. Since energy losses in the batteries, wiring, fuses, and charge controllers are expected to be more than $6 \%$, this indicates that the FSEC systems were in an energy deficit situation for about 3 months during the second winter.

Figure 14 compares state-of-charge measurements for systems 3 \& 4 at Sandia and FSEC. These systems had the same controllers with nominally identical set points at the two laboratories. It is important to remember, however, that the average daily depth of discharge was $15 \%$ at Sandia and $20 \%$ at FSEC. In Figure 14, the Sandia state-of-charge data stays above $90 \%$ state-of-charge for most of the test, ending at about $85 \%$ state-of-charge at 23 months. The FSEC state-ot-charge data drops steadily to final values of $28 \%$ and $46 \%$ in the same time frame. Remembering that the FSEC state-of-charge measurements are probably somewhat higher than the true system state-of-charge makes this difference even larger. Since neither set of batteries had exceeded the manufacturer's expected cycle life in this data, it is probable that the difference in system performance seen in Figure 14 is due to the difference in the array-toload ratio at Sandia and FSEC.

It is useful to look at how the state-of-charge varied on a daily basis for the FSEC systems. During the second winter, 


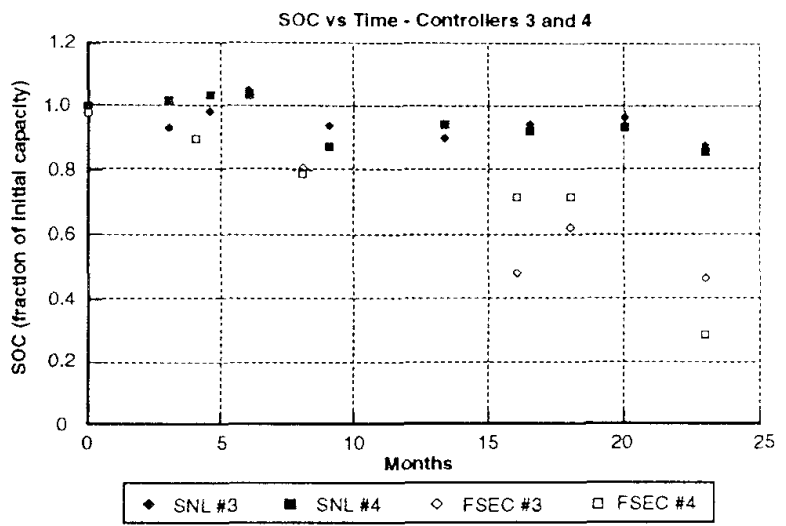

Figure 14: State-of-charge versus time for two sets of nominally identical systems at Sandia and FSEC. These are the systems with the highest Vrr settings.

the avtrage of the state of charge measurements for systems $2-7$ at FSEC was $64 \%$ (We exclude system \#1 because its set points were too (ow). Remember that the true FSEC state-of-charge levels may be $\sim 6 \%$ lower than the values given here. Thus, given the -22 amp-hr nightly load, the systems at FSEC were cycling between $64 \%$ and $41 \%$ stateof-charge on a daily basis. This type of cycling between two relatively low states-of-charge will lead to stratification of the battery electrolyte and sulfation of the battery plates, both of which will shorten the useful life of the battery.

From the relatively high state-of-charge measurements at Sandia and the relatively low measurements at FSEC, we conclude that the 1.31 to 1 array-to-load ratio at Sandia was adequate for proper operation of the PV systems with a 24 hour load. The 1.15 to 1 ratio at FSEC was inadequate for systems with nighttime loads As a caution, we note that the systems at Sandia rarely saw more than three cloudy days in a row. In areas characterized by long $(1-2$ weeks or more) periods of unbroken cloudy weather, it may be necessary to increase the array-to-load levels above those used in the Sandia systems.

\section{Battery Cycle Life}

Since early failure of batteries has been a common problem in PV systems, it is useful to compare the battery lifetime seen in these experiments to the lifetime expected by the battery manufacturer. The Trojan Battery Corporation expects the $30 \mathrm{XH}$ batteries used in these experiments to have a useful cycle life of $\sim 900$ cycles when they are cycled at $15 \%$ depth-of-discharge. At 900 cycles, Trojan would expect its "average battery" to have declined to $50 \%$ of its original capacity and would expect it to fail completely soon thereafter. During the course of these experiments, the batteries at Sandia went through about 690 daily cycles to $15 \%$ depth of discharge in addition to the 17 cycles to $100 \%$ depth-of-discharge, during the initialization and state-ofcharge tests. Since the lifetime for $100 \%$ depth of discharge cycling is only about one-sixth as large as for $15 \%$ cycling, the 690 cycles at $15 \%$ and 17 tests to $100 \%$ were roughly equivalent to 800 cycles at $15 \%$ depth of discharge, or eightninths of the expected life of the battery. At the end of this cycling, the five batteries on the Sandia systems with the highest Vrr values, systems $2,3,4,5 \& 7$, remained above $50 \%$ state-of-charge. Systems 3 and 4 , which had the highest Vrr values, remained above $80 \%$ state-of-charge. Thus, it appears that under the proper conditions, flooded lead-acid batteries can achieve lifetimes in stand-alone PV systems comparable to manufacturer's expectations for more conventional battery uses. It is important to note that the batteries at Sandia were rarely at temperatures higher than $35^{\circ} \mathrm{C}$ and that they were recharged about 4 times a year by a power supply that charged the batteries to $14.4 \mathrm{~V}$ and then held them at that voltage for 10 hours.

\section{Water Loss}

Battery water loss is a common cause of PV system failure. For most systems, the dominant cause of water loss is the over-voltage gassing or electrolysis reaction. ${ }^{16,19}$ This reaction, which is described by a number of authors, ${ }^{19,22,23}$ is a strong positive function of temperature, with hot batteries producing more gas at a given voltage and charging current than cold batteries. The amount of water lost by over-voltage gassing (in the absence of any recombination) and the current driving the gassing reaction are related by: ${ }^{23}$

$$
\mathrm{H}_{2} \mathrm{O}=0.00561 \mathrm{~T}
$$

where:

$$
\begin{aligned}
& \mathrm{H}_{2} \mathrm{O}= \text { grams of water converted to gas per } \\
& \text { cell }
\end{aligned}
$$

In the light of these facts, we can examine the Sandia and FSEC water loss data shown in Figures 15 and 16 and in Table III. Several things are apparent from the figures. First,

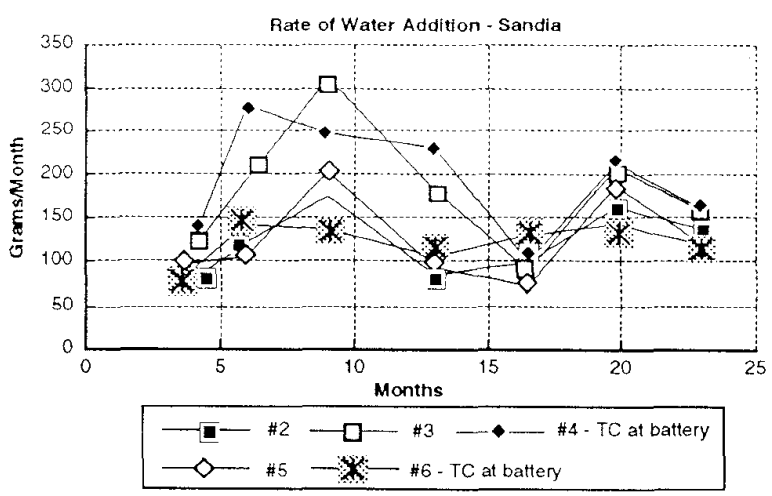

Figure 15: Rate of water addition versus time for some batteries at Sandia. 


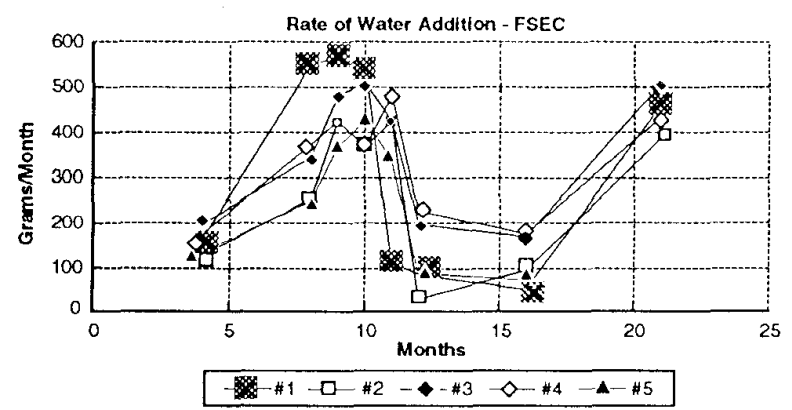

Figure 16: Rate of water addition versus time for some batteries at FSEC. Note the high initial losses of system \#1 which malfunctioned and normally continued to bulk charge the battery regardless of battery voltage. The water loss in system \#1 dropped dramatically after the controller was replaced 10 months into the test.

summer water loss is a factor of 2-to-3 higher than winter loss for most of the systems. Second, summer water loss is about a factor of 2 higher at FSEC than at Sandia. This causes the overall water loss at FSEC to be about $60 \%$ higher than at Sandia. In the summer at FSEC, when water losses were the highest, typical batteries lost $\sim 40 \mathrm{~g}$ of water per month. To account for this loss through the over-voltage gassing reaction would require that 6.5 amp-hrs per day was consumed by gassing in the batteries. Since $6.5 \mathrm{amp}-\mathrm{hrs}$ is a small fraction of the total energy available from the PV array per day, we feel these results are consistent with overvoltage gassing being the dominant battery water loss mechanism in these tests. The fact that summer water losses were higher than winter water losses is consistent with the strong temperature dependence of the over-voltage gassing reaction. The fact that summer water losses were higher at FSEC than Sandia is also consistent with the temperature dependence of the gassing reaction and the fact that summer temperatures were higher at FSEC than at Sandia (Figure $5)$.

There is some evidence from the Sandia data that temperature compensation of the controller set points does smooth out the summer-to-winter water loss cycle. In Figure 15 , system 6 at Sandia had temperature compensation based on the battery temperature with a coefficient of approximately $-30 \mathrm{mV} /{ }^{\circ} \mathrm{C}$ or $-5 \mathrm{mV} /{ }^{\circ} \mathrm{C}$ per cell. This system has a much smaller summer-to-winter variation than the other systems. System 4 at Sandia, which was kept at a much higher state of-charge, also had temperature compensation with a coefficient also of about $-30 \mathrm{mV} /{ }^{\circ} \mathrm{C}$. We can compare system 4 to system 3 at Sandia, which had a similar state-of-charge, but did not have temperature compensation. During the first year, system 4 does lose more water in cool weather and less water in hot weather than system 3 . However, this effect is not apparent in the second year. The effects of the very high voltages $(\sim 15.0-15.3 \mathrm{~V})$ attained on system \#1 at FSEC are apparent in Figure 16. System one has very high water use until the charge controller was replaced during the 10th month, after which the water loss drops sharply.

\section{Specific Gravity Measurements}

In these experiments, specific gravity measurements were taken just before measuring battery state-of-charge. In order to minimize the impact of local gradients in the electrolyte, these specific gravity measurements were taken after the batteries had been disconnected from the PV array and load for at least 14 hours but less than 20 hours. Figure 17 shows a plot of battery state-of-charge as a function of the average

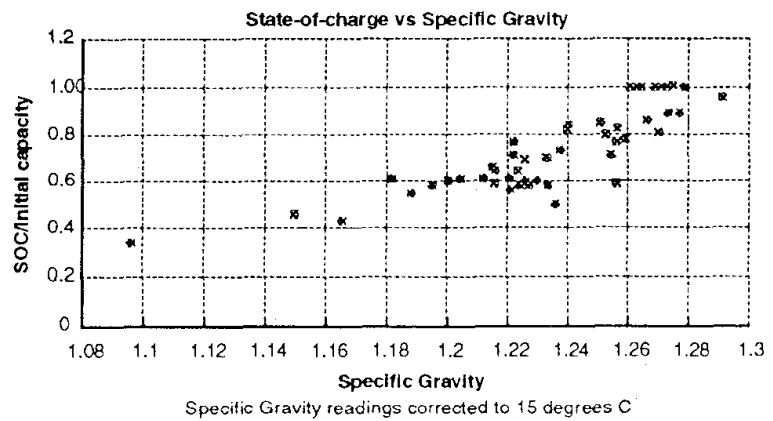

Figure 17: Battery state-of-charge versus average specific gravity of the six cells in each battery. While the variables are clearly correlated, there is enough scatter in the data to prevent specific gravity from being used as an accurate gauge of state-of-charge.

specific gravity in the six cells in each battery for the systems at Sandia. These specific gravity measurements are corrected to $25^{\circ} \mathrm{C}$. Note that these tests were performed on nominally identical batteries that were all purchased from the manufacturer at the same time. Although there is clearly a correlation between state-of-charge and specific gravity $(\mathrm{R}=0.84, \mathrm{P}=$ less than $0.1 \%$ ), there is considerable scatter in the data. Nearly identical values of specific gravity in Figure 17 correspond to state-of-charge measurements that differ by almost $30 \%$. This variation, which may be due to the fact that these measurements were taken using the electrolyte from the top surface of batteries which had significant electrolyte stratification, makes specific gravity measurements only a rough measurement of battery stateof-charge when performed on aging batteries in field situations.

\section{CONCLUSIONS}

Conclusions for controller and system design are:

1. Battery state-ot-charge was strongly correlated with the value of the regulation reconnect voltage $(\mathrm{Vrr})$. Over the limited range of regulation voltages tested at Sandia $(14.25 \mathrm{~V}$ to $14.54 \mathrm{~V})$ battery state-of-charge was only 
weakly related to the value of the regulation voltage. It appears that the number of times a system cycles off and on in regulation, which is determined by the regulation reconnect voltage, is more important than the maximum voltage reached in any one cycle. At some point beyond the narrow range of regulation voltage settings investigated here, it is clear that regulation voltage settings will become more important.

2. The data taken at Sandia demonstrate that Trojan's 30XH flooded lead-acid battery with lead-antimony grids, when operating in a PV system, can achieve cyclelifetimes which are comparable to manufacturer's expections for conventional battery applications. It is important to note that the batteries which met manufacturer's expectations were maintained at a high state-of-charge, rarely exceeded temperatures of $35^{\circ}$ $\mathrm{C}$ and that about four times a year these batteries were recharged by a power supply that charged the batteries to $14.4 \mathrm{~V}$ and then held them at that voltage for 10 hours.

3. The systems tested here had battery capacities equal to $\sim 4$ days load requirements and array-to-load ratios ranging from 1.15-to-1 to 1.31-to-1. For these systems, both the overcharge protection and the overdischarge protection provided by the charge controllers were required for reliable system operation and acceptable battery lifetime.

4. The array-energy-input to load-energy-requirement ratio ("array-to-load ratio") in the worst month of a "typical meteorological year" is an important parameter affecting the overall health of a PV system. The data in these tests indicate that with a load operating only at night, the array-to-load ratio of 1.15 to 1 at FSEC was inadequate for proper operation of the PV systems. The array-to-load ratio of 1.31 to 1 at Sandia was adequate when operated with a 24-hour-per day load.

5. For PV systems that spend a significant amount of time in an energy-deficit situation, increasing the value of the low-voltage cutoff significantly improves the long-term health of the battery, at the expense of decreasing the load availability.

6. While there was clearly a relationship between battery state-of-charge and specific gravity of the battery electrolyte, the scatter in the data is too large for specific gravity measurements to be used as an accurate measurement of battery state-of-charge when performed on aging batteries in field situations. Field measurements of specific gravity still have considerable value in diagnosing failed or marginal cells.

7. Charge controllers which operate at high frequency or in a current limiting mode can generate heat internally during the regulation cycle and in some cases this can raise the temperature of the charge controller $30^{\circ} \mathrm{C}$ above ambient temperatures. Therefore, external temperature compensation probes that measure battery temperature directly are preferable to temperature compensation probes located inside the charge controller.

\section{Conclusions for battery water loss:}

8. For the flooded lead-acid batteries tested here, battery water loss is directly related to the battery state-ofcharge. In general, the higher the state-of-charge, the higher the water loss. Allowance for this water loss needs to be included in system design or maintenance plans.

9. Battery water loss varied by a factor of 2 to 3 from summer to winter. The amount of battery water loss seen in these experiments can be accounted for by the over-voltage gassing reaction and variations in the battery temperatures. The fact that the summer water losses at FSEC were more than a factor of two higher than the losses at Sandia is consistent with the fact that the batteries were hotter at FSEC than Sandia in the summer and the fact that the overvoltage gassing rate increases with increasing temperature.

10. Temperature compensation of the charge controller set points can reduce the size of the summer-to-winter water loss cycling, but did not reduce overall system water loss for the systems tested here. It should be noted however, that temperature compensation is also expected to reduce grid corrosion in hot weather and help maintain a high state-of-charge in cold weather. Our data does not give any information on these latter two factors.

\section{ACKNOWLEDGMENTS}

Many people contributed to these experiments. We would like to acknowledge a number of helpful conversations with the charge controller manufacturers, with Jim Drizos of the Trojan Battery Corporation and with Garth Corey, Rudy Jungst, and Jim Freese of Sandia's Storage Batteries Department. We also wish to acknowledge that this paper drew heavily on internal reports at Sandia ${ }^{24}$ and FSEC. ${ }^{25}$ This work was supported by the U. S. Department of Energy under contract DE-AC04-94ALB50009.

\section{REFERENCES}

1. Lisa Shepperd and Elizabeth H. Richards, Solar Photovoltaics for Development Applications, Florida Solar Energy Center and Sandia National Laboratories, 1993. Available from PV Design Assistance Center Sandia National Laboratories, Mail Stop 0752, Sandia National Laboratories, POB 5800, Albuquerque, NM 87185-0752, (505) 844-3698.

2. Michael G. Thomas, Harold N. Post, Anne VanArsdall, Photovoltaics Now - Photovoltaic Systems for Government Agencies, Sandia National Laboratories SAND88-3149, Revised February 1994, Available from 
PV Design Assistance Center at Sandia.

3. Herbert Wade, Photovoltaic Rural Electrification Projects in the Pacific Region and Lessons Learned, South Pacific Institute for Renewable Energy, BP 11530, Mahina, Tahiti, French Polynesia. This report was prepared for the World Bank as part of its 1991 Pacific Regional Energy Assessment.

4. Jorge M. Huacuz, Roberto Flores, Jaime Agredano, Gonzalo Munguia, Field Performance of Lead-Acid Batteries in Photovoltaic Rural Electrification Kits, Instituto de Investigations Electricas, Division Fuentes de Energia, Departmento de Fuentes NoConvencionales de Energia, Apartado Postal 475. Cuernavaca, Mor. 62000, Mexico, May 1994.

5. Ward I. Bower, James P. Dunlop, Craig W. Maytrott, Performance of Battery Charge Controllers: An Interim Test Report, Proceedings of the 21st IEEE PV Specialists Conference, 1990 , p. 1122, IEEE publication \#0160-8371/90/000.

6. James P. Dunlop, Ward Bower, Steve Harrington, Performance of Battery Charge Controllers: First Year Test Report, Proceedings of the 22nd IEEE PV Specialists Conference, 1991, p. 640, IEEE publication \#CH2953-8/91/000.

7. John Stevens, Jay Kratochvil, Steve Harrington, Field Investigation of the Relationship Between Battery Size and PV system Performance, Proceedings of the 23rd IEEE PV Specialists Conference, May 1993, p. 1163, publication \#93CH3283-9

8. Trojan Battery Company, 12380 Clark St, Santa Fe Springs, CA 90670; (800) 423-6569

9. Bobier Electronics Inc, 512 37th St. POB 1545, Parkersburg, West Virginia, 26101, (304) 485-7150.

10. BOSS has been purchased by Photocomm Inc, 7681 E. Gray Rd. Scottsdale, Arizona, 85260, (602) 948-8003.

11. Heliotrope General, 3733 Kenora Dr. Spring Valley CA, $91977,(800)$ 552-8838

12. Integrated Power Corporation: 7524 Standish Place, Rockville, Md 20855; (301) 294-9133

13. Polar Power: 2808 Oregon Ct. Bldg K-4, Torrance, CA 90503; (310) 320-3514

14. Specialty Concepts Inc, 8954 Mason Ave, Chatsworth CA 91311, (818) 998-5238

15. SunAmp Power: 1902 Country Club Dr, No. 8, Mesa AZ 85201; (602) 833-1550.

16. Jim Drizos, Trojan Battery Corporation, private communication.

17. PVCAD, Version $2.10 \mathrm{C}$, available from Photovoltaic Resources International, 1902 N. Country Club Dr. \#6 Mesa, AZ 85201, (602) 834-7778

18. Solar Radiation Data Manual for Flat Plate and Concentrating Collectors, National Renewable Energy Laboratory, 1617 Cole Blvd, Golden, Colorado, NREL/ TP-463-3393, 1994.

19. Richard A. Perez, The Complete Battery Book, TAB Books Inc. Blue Ridge Summit, PA, 1985, pps. 22 and 36.

20. V. Alminauskas, Performance Evaluation of Lead Acid Batteries for Use with Solar Panels, Proceedings of the 23rd IEEE PV Specialists Conference, May 1993, p. 1258, IEEE publication \#93 $\mathrm{CH} 3283-9$

21. Philip R. Bevington, Data Reduction and Error Analysis for the Physical Sciences, McGraw-Hill Book Co, New York, 1969, pps. 119 \& 312.

22. David Linden, Handbook of Batteries and Fuel Cells, McGraw Hill, New York City, 1984, ISBN 0-07-037874. 6. Out of Print - but available from Independent Battery Manufacturer's Assn, 100 Larchwood Dr, Largo, FL 34640-2811, (813) 586-1408.

23. Elsevier Sequoia and S. A. Lausanne, Lead Acid Batteries, A Reference and Data Book, Indian Lead Zinc Information Centre, New Deli, 1977, p. 116.

24. Steven R. Harrington, PV Battery/Charge Controller Tests at Sandia National Laboratories - Phase One, issued in draft form 4/19/94.

25. James P. Dunlop, Evaluation of Battery Charge Controllers - Phase 1 and 2 Summary, FSEC-CR516-92, September 1992 . 